\title{
Interactive comment on "Experimental tests of phytoplankton response to ornithological eutrophication in Arctic freshwaters" by Heather L. Mariash et al.
}

\section{Anonymous Referee \#2}

Received and published: 10 July 2019

In this manuscript Mariash and co-workers investigate the impact of goose faeces on water chemistry and phytoplankton communities in arctic freshwaters. The authors present results from a mesocosm experiment in which goose faeces and Carex leaves were added in different treatments. In the experiment the development of water chemistry ( $\mathrm{C}, \mathrm{P}$ and $\mathrm{N}$ ) and phytoplankton community were followed. Estimated goose faeces loading rates, water chemistry and chlorophyll data (unpublished data) from a previous study by the authors in the Southhampton area were compared to with results from other studies in USA and Canada.

Given the increasing goose populations in the arctic and the impact they have on the 
arctic environment the subject of the manuscript is highly relevant. This is especially true considering that the main focus within this subject so far has been on goose impacts in the terrestrial environment while little attention has been devoted to impacts on the freshwater environment. The manuscript is well written and the language fluent. However, I do have some major comments that detracts from the overall impression of the manuscript.

A major comment concerns the focus of the manuscript as related to the results presented. The title gives the impression that this is a story about goose/bird mediated impact on phytoplankton communities in arctic freshwaters. Furthermore, a large part of the text is devoted to phytoplankton. However, in my mind the strong part of the data presented are the results on changes in water chemistry in response to addition of goose faeces. In fact, it is quite interesting to see how rapid the nutrients from the faeces are released into the water. Due to the limitations outlined below, I do not think that the phytoplankton data presented are substantial enough to back up a main focus on effects on the phytoplankton community.

3 out of 10 (or 8?) phytoplankton samples from the experiment could not be counted due to insufficient fixation. This is a significant part of the samples, especially since the missing samples were from day 1 in the goose faeces treatment and from day 3 and 5 in the Carex treatment, respectively. This made it impossible to compare the phytoplankton response between treatments on day 1,3 and 5 , which is the most important period of the experiment in my mind.

The experimental design is clear. However, a consequence of the phytoplankton sampling, where three replicates (per sampling day/treatment) were pooled, there is just one observation/replicate on phytoplankton biovolume/composition per sampling day/treatment. Considering the focus of the manuscript on phytoplankton responses, it would have been good with more observations/replicates to get an idea about the variation in the phytoplankton response.

Printer-friendly version

Discussion paper 
It is stated that one of the aims was to measure changes in phytoplankton productivity. In the methods it is explained that phytoplankton production rates were estimated from changes in biovolumes between different sampling days. Thus, it is not the phytoplankton productivity that is measured but phytoplankton biovolumes. In the results section no production estimates are presented. Here, only the changes in the biovolumes are mentioned. I guess, this is due to the lacking phytoplankton samples mentioned above making comparison between treatments impossible throughout most of the period that phytoplankton was sampled in the experiments.

Phytoplankton taxa were identified to genera. Species within the same genera may show different responses to a given environmental change, e.g. eutrophication. Hence, a better taxonomical resolution in the identification would have made it possible also to get an idea about the species specific responses to the experimental treatments.

For reasons outlined above, I do not think the data presented on phytoplankton justifies the focus in the manuscript on phytoplankton response to goose impacts in arctic freshwaters. However, the data presented on the changes in water chemistry in the goose treatment are very interesting. Especially the rapid release of nutrients from the goose faeces brings new insights. I suggest the authors rework the manuscript to "Experimental tests of water chemistry to goose mediated (or ornithological?) eutrophication in Arctic freshwaters", leaving out the phytoplankton data from the manuscript.

Minor comments: In the introduction there is a focus on the nutrient enrichment as the mechanistic explanation for the goose impact on arctic freshwaters. I agree that this is likely an (the most) important mechanism in explaining goose impacts. Still, dispersal effects in the experiments cannot be completely excluded due to the way goose faeces additions were done (no treatment of the faeces was done, e.g. heating, before addition to the experimental beakers). Hence, differences in phytoplankton composition between treatments could also, at least partly, be caused by input of phytoplankton spores/cysts with the goose faeces. This is not a criticism of the experimental setup, but I think this issue should be mentioned in the manuscript (introduction and discus-

Printer-friendly version

Discussion paper 
sion) as long as the phytoplankton aspect is included in the manuscript. P. 5 I. 15-16: "(for sampling details see Mariash et. al. 2018, Table 3)" instead of "(for sampling details see Mariash et. al. 2018)(Table 3)". P. 5 I. 27-28: Production rates are not included in the results section. P. 5 I. 28: include identification literature. P. 6 I. 4-5: "To model the effect of our treatments on primary productivity, we used a linear mixed effects model implemented in Ime4 (Bates et al., 2014)." As far as I can see these results are not included in the results section, likely due to the lacking phytoplankton data. P. 7 I. 8-16: This text passage seems a bit strange due to the lacking phytoplankton data. This also applies to I. 24-26 on p. 7. P. 7 I. 23: delete "(“. P. 9. L. 19: "We had expected phytoplankton production to be higher in the goose dropping treatment vs. the Carex treatment". As noted above phytoplankton itself is not measured. Thus, it seems safer to use "phytoplankton biovolume". P. 9 I. 28-32: Also, this text passage seems a bit strange due to the lacking phytoplankton data. Figure 4: it is difficult the distinguish the colors used for some of the phytoplankton classes, e.g. dinophyceae, euglenophyceae and fragilariophyceae. Maybe use different patterns in grey tones instead.

Interactive comment on Biogeosciences Discuss., https://doi.org/10.5194/bg-2019-160, 2019.

Printer-friendly version

Discussion paper 